

\section{Innate and Adaptive Immunity}

The immune system is finely orchestrated by a myriad of cell types and mediators that are required to be tolerant of self but responsive to alterations perceived as non-self. The first line of defense against non-self is a nonspecific response by cells such as macrophages, neutrophils, dendritic cells (DCs), and natural killer (NK) cells, which are part of the innate immune system. The innate immune response is then followed by coordination of antigenspecific recognition via lymphocytes, which are part of the adaptive immune system and that provide long-term memory. These two distinct compartments, innate and adaptive, communicate via sophisticated networks that allow for an activated immune response when an appropriate "danger" signal is perceived and regulation of the response so as to prevent continuous proliferation of immune cells. This complex system has evolved to simultaneously provide tolerance to self, eliminate pathogens, and control an activated immune response in order to prevent self-damage. In order to harness the power of this biological machinery for the treatment of cancer, it is necessary to understand some of the basic principles that govern this system. Rational design of immunotherapeutic agents is an ongoing process that targets some of these principles for the generation of tumor-specific immune responses.

The primary mechanism for an immediate response to infection or cellular injury is via innate immunity. The innate immune system uses germline-encoded or pathogen recognition receptors (PRRs) to identify pathogen-associated molecular patterns (PAMPs) on microbes. ${ }^{3}$ Receptor signaling leads to production of cytokines, proteases, reactive oxygen species, and other inflammatory mediators in order to recruit leukocytes to the area of injury. This inflammatory response, when limited and controlled, provides for host responses, including endothelial and fibroblast responses, to initiate a first-line defense against injury and repair of damage. In situations of chronic inflammation, due to disruptions of innate and/or adaptive immune cells, tissue destruction, and eventual DNA damage, may lead to disease states, including cancer.

PRRs include toll-like receptors (TLRs), which are widely expressed on innate immune cells and consist of 13 receptors known to date. Although all TLRs are structurally similar and recognize conserved molecular patterns on microbes, it has been demonstrated that signaling via specific TLRs can induce distinct responses. For example, viral and intracellular bacterial DNA will induce signaling via TLR9, which leads to interferon (IFN)- $a$ production, favoring a Th1 profile, as well as enhanced cytotoxic T-lymphocyte (CTL) responses. ${ }^{4}$ Conversely, stimulation of TLR2 by acylated outer membrane lipoproteins of gram-positive bacteria can result in interleukin (IL)-10 production, which favors a bias towards a Th2 profile or regulatory T-cell responses. ${ }^{5}$

While bacterial cells express TLR ligands, it should be noted that tumor cells do not. Therefore, appropriate adjuvants, which provide TLR signaling via the innate immune system, can be used with immunotherapeutic agents to enhance immune responses. Potent stimulators of the innate immune system may provide an effective immune response against tumor cells. This mechanism may be the most likely way in which intravesical BCG exerts its influence in the treatment of superficial bladder cancer. 
Although the exact mechanism of action of intravesical BCG in the treatment of bladder cancer is poorly understood, recent evidence continues to corroborate an immunological mechanism. BCG plays a significant role in the maturation of DCs by signaling through different TLRs, as indicated by its upregulation of the DC maturation marker CD83 ${ }^{6}$ and secretion of inflammatory cytokines such as IL-12, IFN- $\gamma$, and tumor necrosis factor (TNF)$a$. A variety of cytokines has been detected in the urine of patients treated with intravesical BCG, and BCG causes an influx of granulocytes and mono-nuclear cells into the bladder wall. ${ }^{7-14}$ Although the significance of these infiltrating cells remains controversial, we recently studied intratumoral lymphocytes in urothelial carcinoma and determined that the presence of $\mathrm{CD} 8^{+} \mathrm{T}$ cells correlated with better disease outcome in patients with more advanced disease. ${ }^{15}$ Improved clinical outcomes have been noted in association with the presence of intratumoral T cells in ovarian, ${ }^{16}$ esophageal, ${ }^{17}$ and colorectal carcinomas. ${ }^{18}$ It is possible that activation of the innate immune system by intravesical BCG leads to stimulation of an antigen-specific adaptive response, associated with T-cell infiltration, that allows for eradication of tumor cells. The identification of the tumor antigen(s) that these $\mathrm{T}$ cells recognize may provide a potential vaccine target for the development of specific immunotherapy for bladder cancer.

Activation of the innate immune system is crucial for establishing an effective adaptive immune response. Activated antigen-presenting cells (APCs) from the innate immune system, such as DCs, migrate to lymphoid organs, such as lymph nodes, and present antigens to adaptive immune cells, such as T cells. Similarly, inflammatory cytokines produced by innate immune cells recruit adaptive immune cells, including B and T cells, thereby propagating a more specific immune response.

Adaptive immune cells, such as B and T cells, in contrast to innate immune cells, express somatically generated antigen-specific receptors, which are formed as a result of random gene rearrangements to allow for a diverse repertoire. These somatically rearranged receptors allow for specific recognition of a vast array of antigens. B-cell recognition of intact antigen via immunoglobulin receptor leads to proliferation of the B cell and secretion of neutralizing antibodies against the antigen. The clonal expansion of an antigen-specific $\mathrm{B}$ cell subsides after elimination of the antigen, and a resultant pool of memory B cells will exist to provide for a rapid antibody response against subsequent exposure to the antigen. Similarly, T cells recognize antigens via a specific T-cell receptor (TCR). However, unlike B cells, $\mathrm{T}$ cells require processed antigen to be presented in the context of the major histocompatibility complex (MHC).

Classical MHC molecules comprise class I and class II proteins, which enable each individual's immune system to distinguish self from non-self. TCRs of $\mathrm{CD}^{+} \mathrm{T}$ cells (cytotoxic T cells) recognize antigen in the context of class I MHC, and TCRs of CD4 ${ }^{+} \mathrm{T}$ cells (helper T cells) recognize antigen in the context of class II MHC. The initiation of selftolerance occurs early in development as a process of positive and negative selection when $\mathrm{T}$ cells interact with thymic APCs that express self-MHC molecules bearing self-antigens. The avidity between TCRs and MHC plus self-peptides determines the fate of T cells, such that high- and low-avidity interactions lead to negative selection of T cells, while intermediateavidity binding allows for positive selection. Therefore, circulating $\mathrm{T}$ cells in cancer patients 
are already selected for their ability to ignore self-antigens, which are the majority of tumor antigens. However, in certain patients, there are tumor-infiltrating lymphocytes that tend to correlate with improved outcomes, thus indicating the possibility of manipulating the immune system to favor tumor-reactive T cells. Furthermore, apart from TCR engagement of MHC plus antigen (signal 1), additional signals and costimulatory molecules (signal 2) are necessary to attenuate the T-cell response and create an activated T cell. Upon T-cell activation, there are also "co-inhibitory" signals generated to regulate the T-cell response and limit T-cell proliferation. The interplay of these signals provides opportunities to target Tcell pathways in an effort to induce anti-tumor immunity.

\section{T-Cell Activation and Costimulatory Signals}

Crucial elements of cellular immune responses are the activation, clonal expansion, and differentiation of $\mathrm{T}$ cells. The signal transduction events during activation of cytotoxic and helper $\mathrm{T}$ cells are generally similar. In addition, activation of either population of $\mathrm{T}$ cells is not an independent process but may be influenced largely by the other. Activation of T cells can be divided into two phases reflecting different aspects of the response. The first phase activates naive $\mathrm{T}$ cells and differentiates them into functional effector cells; in the second phase, these effector cells recognize antigen on specific target cells, which results in the destruction of the target cell.

Activation of naive $\mathrm{T}$ cells and their subsequent differentiation into effector cells requires the primary signal via the TCR and co-receptor, CD4 or CD8, as well as costimulatory signals. In contrast, antigen-experienced cells are able to respond to TCR-mediated signals with little, if any, costimulation. These differences are at least in part due to the expression of distinct isoforms of the CD45 protein, that is, CD45RA and CD45RO. ${ }^{19}$ These isoforms are generated by alternative splicing of the mRNA transcript, and the resulting proteins exert a phosphatase activity that catalyzes dephosphorylation of the protein tyrosine kinases, Lck and Fyn, that are responsible for subsequent steps of T-cell activation. ${ }^{20}$ Notably, CD45RO, expressed on memory T cells, exhibits stronger association with the TCR and its coreceptors than CD45RA, improving the efficiency of the TCR signaling. The evolution of naive $\mathrm{T}$ cells to memory/effector cells involves multiple proteins, some of which can be used as markers to identify the different T-cell stages. ${ }^{21}$

Additionally, the nature of the antigenic epitope also influences the outcome of TCRmediated signaling. Complete peptide agonists stimulate the cell to become activated and proliferate while partial-agonist peptides may induce a measurable T-cell response, such as production of IFN- $\gamma$, with minimal proliferation or no proliferation. Many models of T-cell activation have been proposed to explain the differential effects of altered peptides. These models include changes in the kinetics of signal transduction, formation of the immunologic synapse, induction of a negative signal, and recruitment of TCR or costimulatory molecules.

The best-characterized costimulatory signaling system required for the activation of naive $\mathrm{T}$ cells is based on the interaction of B7 family members with CD28 and CTL-associated antigen 4 (CTLA-4). ${ }^{22}$ The CD28 family includes the following five members: CD28, CTLA-4, inducible T cell co-stimulator (ICOS), programmed death-1 (PD1), and B- and T- 
lymphocyte attenuator (BTLA). The B7 family currently includes seven known members: B71, B72, ICOS-L, PD-L1, PD-L2, B7H3, and B7x/B7H4. The B7-CD28/CTLA4 pathway is rather complex because of the dual specificity of B7-1 (CD80) and B7-2 (CD86), located on $\mathrm{T}$ cells, for the stimulatory receptor CD28 and the inhibitory receptor CTLA-4 (CD152), located on APCs.

Research over the past decade has established that engagement of CD28 by B7-1 and B7-2 provides signal 2, at least for naive T cells, while B7-CTLA-4 interactions inhibit T-cell responses and regulate peripheral T-cell tolerance. A fundamental issue in the CD28 CTLA-4 system is how a process regulated by the integration of positive and negative signals, generated by receptors that bind the same ligands, can ever be activated when the affinity of the inhibitory receptor for the ligand greatly exceeds that of the stimulatory receptor. The answer seems to involve the temporal and spatial separation of expression of CD28 and CTLA-4. CD28 is constitutively expressed on the surface of T cells, whereas CTLA-4 expression is rapidly upregulated after T-cell activation. ${ }^{23}$ The binding of CTLA-4 to $\mathrm{B} 7$ serves to negatively impact $\mathrm{CD} 28-\mathrm{B} 7$ interactions and thereby regulates T-cell activation $^{24}$ (Fig 1). CTLA-4 appears to determine the "burst size" of responding T-cell clones. Furthermore, CTLA- 4 serves to limit the proliferation of T cells as evidenced by the fact that CTLA-4 knockout mice develop early and fatal lymphopro-liferation. ${ }^{25-27}$ However, CTLA-4 -mediated inhibitory signals are not constitutively or uniformly generated during the process of T-cell activation. While CTLA-4 function is restricted by spatial and temporal constraints, these constraints are, in turn, regulated by the stimulatory conditions under which T-cell activation occurs. Thus, the ability of CTLA-4 to restrict the activation of any one $\mathrm{T}$ cell will depend on a variety of variables, including the strength of the TCR signal and the activation state of the APC.

In summary, activation of naive $\mathrm{T}$ cells occurs when appropriate innate immune cells, such as DCs, present antigen in the context of MHC to engage a specific TCR, and additional costimulatory signals are delivered. The efficiency of T-cell activation is due in large part to the nature of the TCR stimulation, as well as the costimulatory signal. Once activated, T cells will produce cytokines, as seen with $\mathrm{CD}^{+}$helper $\mathrm{T}$ cells, to assist $\mathrm{B}$-cell production of antibodies, enhance recruitment of other cell types, and deliver signals for increased proliferation of cells such as $\mathrm{CD}^{+}$cytotoxic $\mathrm{T}$ cells, which are necessary to kill tumor cells. Based on these principles, immunotherapy strategies in cancer patients have focused on delivering appropriate immunologic adjuvants, capable of activating the innate immune system possibly via TLR signaling, in conjunction with antigens that can bind strongly to TCR in order activate the adaptive immune system.

\section{Stimulating T Cells for Cancer Immunotherapy}

Our current understanding of the immune system points to $\mathrm{T}$ cells as critical players in the elimination of infected and neoplastic cells. As discussed earlier, the trimolecular complex formed between the MHC, the peptide ligand, and the TCR represents the elementary structural unit ultimately responsible for cellular immune recognition and activation against antigenic stimuli. ${ }^{28}$ Although the engagement of TCRs with MHC/peptide complexes is essential for immune recognition, initiation and regulation of the immune response also 
requires antigen-independent, receptor-ligand interactions, known as costimulation. ${ }^{29} \mathrm{In}$ contrast to CD28/B7 engagement, which provides a "positive" signal important for lymphocyte activation and proliferation, CTLA4/B7 transduces an opposing "negative" signal, leading to subsequent downregulation of T-cell-mediated immune responses. ${ }^{24}$ Probably the integration and balance of signals coordinated via these two distinct arms ultimately dictates the intensity of T-cell activation and clonal expansion and the longevity of the T-cell-mediated immune reaction. Therefore, enhancing the pool and efficacy of T cells has been the focus of many vaccination strategies.

Several immunotherapy strategies that have been attempted include delivery of irradiated or modified tumor cells or cell lysates (cellular vaccines), administration of tumor-associated antigen vaccines in various forms (peptide, protein, DNA, or DC-pulsed), and isolation of infiltrating $\mathrm{T}$ cells from patient tumors with stimulation of these $\mathrm{T}$ cells in vitro followed by injection back into patients (tumor infiltrating lymphocyte [TIL] vaccines). Our strategy in bladder cancer has focused on tumor-associated antigen vaccines.

Bladder cancer cells express several cancer-associated antigens, including a variety of cancer-testis (CT) antigens. CT antigens comprise one of the most specific tumor-antigen families discovered to date, and have received attention as targets for cancer vaccine development. In the 1990s, T-cell epitope cloning led to identification of new tumor antigens known as MAGEA $1,{ }^{30}$ BAGE, ${ }^{31}$ and GAGE $1 .{ }^{32}$ The mRNA encoding these gene products was shown to be present exclusively in normal testis and in some types of cancer. In 1995, with the introduction of the serologic expression cloning ("SEREX") approach, many more antigens were discovered, including SSX-2 and NY-ESO-1. ${ }^{33,34}$ These antigens share some common characteristics, such as their expression being limited to gametogenic tissues and cancers and an increased frequency of expression in advanced tumors. In recognition of this expression profile, shared by otherwise unrelated genes, the term "CT antigen" was introduced.

To date, 44 distinct CT gene or antigen families have been identified by techniques such as SEREX, T-cell epitope cloning, representational difference analysis, and bioinformatics analysis. ${ }^{35}$ Of the 44 currently known CT family members, 19 have demonstrated immunogenicity as measured by antibody or T-cell responses. These antigens are also expressed in various tumor types, as detected by reverse transcriptase-polymerase chain reaction (RT-PCR) and immunohistochemical analyses.

NY-ESO-1 is the most immunogenic of any of the CT antigens; up to $50 \%$ of patients with advanced NY-ESO-1-positive tumors develop spontaneous humoral and cellular immunity to NY-ESO- $1 .{ }^{36,37}$ Studies of patients with cancer have revealed human lymphocyte antigen (HLA)-A2-restricted and HLA-A24 -restricted CD8 ${ }^{+}$T-cell responses to the NY-ESO-1 antigen. ${ }^{38,39}$ Additional studies of patients with melanoma identified NY-ESO-1-specific CD4 ${ }^{+}$T-cell recognition of the DRB1*0401-restricted epitope and the DRB4*0101-0103restricted epitope. ${ }^{40,41}$

The function of the NY-ESO-1 protein is unknown. The genes encoding NY-ESO-1 and its homolog, LAGE-1, both have been mapped to chromosome Xq28. ${ }^{42}$ LAGE-1 encodes an 
antigen closely related to NY-ESO-1, with $94 \%$ nucleotide and $87 \%$ amino acid homology. ${ }^{43}$ Many types of tumors, most notably advanced tumors, express NY-ESO-1. Our investigation of NY-ESO-1 and LAGE-1 expression in specimens from 121 patients with transitional cell carcinoma (TCC) demonstrated that one or both of these antigens were expressed in 39 of 82 (48\%) high-grade TCC samples and in three of 22 (14\%) low-grade TCC samples. ${ }^{44}$ This study of TCC led to the discovery of a new NY-ESO-1 epitope in the context of HLA-B35 that is recognized by NY-ESO-1-specific CD8 ${ }^{+}$T cells. ${ }^{44}$ Furthermore, we have recently identified additional CT antigens that are highly expressed on urothelial carcinomas and may potentially serve as vaccine targets. ${ }^{45}$

Currently, vaccine clinical trials are under way that use the NY-ESO-1 antigen for patients with bladder cancer. The first trial, currently closed to accrual at Memorial Sloan-Kettering Cancer Center, was aimed at studying the safety of and immune responses to the NY-ESO-1 protein antigen in patients undergoing vaccination as adjuvant therapy, ie, after radical cystectomy or nephroureterectomy to remove visible disease. The six patients enrolled in this trial were given $75 \mu \mathrm{g}$ of NY-ESO-1 recombinant full-length protein weekly for 6 weeks, with BCG for the first 2 weeks and granulocyte-macrophage colony-stimulating factor (GM-CSF) for the remaining 4 weeks, as immunologic adjuvants. Immune responses were variable, but all six patients demonstrated an immune response to the NY-ESO-1 antigen. At a median survival time of 16 months, four of the six patients remained diseasefree. Toxic effects and adverse events were minimal and mostly involved injection site reactions.

The advantage of a full-length antigen vaccine, such as protein or DNA, as compared with a peptide vaccine, is that full-length antigen provides multiple epitopes that can be recognized by different TCRs, on both $\mathrm{CD}^{+}$and $\mathrm{CD} 8^{+} \mathrm{T}$-cell subsets, for the generation of a stronger immune response to the tumor antigen. A particle-mediated epidermal delivery (PMED) system can be used for DNA vaccines. The PMED system accelerates plasmid DNA coated onto gold particles into the skin. Once in the superficial skin layers, the plasmid is designed to transiently express the transgene in resident APCs in the epidermis with subsequent activation and migration of the APCs within the innate immune system. There is increasing evidence that cutaneous DCs can be directly transfected, activated, and trafficked to the regional lymph nodes, where they efficiently stimulate proliferation of antigen-specific $\mathrm{CD}^{+}$and $\mathrm{CD}^{+} \mathrm{T}$ lymphocytes. Previous studies demonstrated that 24 hours after PMED of a plasmid vector encoding a green fluorescent protein (GFP), gold particle-containing cells positive for GFP were found in the draining lymph nodes, indicating successful DNA transfection followed by migration of the antigen-presenting DCs to lymph nodes. 46 Conversely, intramuscular (IM) injection of naked DNA, as opposed to delivery by PMED, leads to antigen uptake by other nonprofessional APCs due to the paucity of resident DCs in the IM compartment. ${ }^{47}$ Our clinical vaccine trial with NY-ESO-1 DNA delivered by PMED relies on vaccine activation of DCs within the innate immune system and subsequent activation of the adaptive immune system.

Related vaccine clinical trials in bladder cancer that are already completed include a study ${ }^{48}$ in which the CT antigen MAGE-3 was used as a peptide vaccine loaded onto autologous DCs, and another study ${ }^{49}$ of a recombinant MAGE-3 protein. Both trials demonstrated 
safety of vaccination and provided some evidence of immune and tumor responses. However, data demonstrating clinical efficacy are still lacking in the field of vaccine immunotherapy. One reason for this shortcoming is our limited ability to assess reliably immunotherapy strategies in the tumor microenvironment, which prevent incremental advances in clinical application. A second reason is the lack of immunologic adjuvants that can target the innate immune system effectively. A third reason is the prevalence of regulatory mechanisms that limit immune responses. Our approach to overcoming these limitations is to perform clinical studies that will be more likely to be informative, with a focus on the development and application of reproducible assays to demonstrate effects in the context of new therapies; employing novel combinations of adjuvants in our vaccine strategies; and developing vaccine strategies in conjunction with therapies aimed at the inhibitory components of the immune system.

T-cell subtypes with inhibitory immune function are currently under investigation as immunotherapy targets. Regulatory $\mathrm{T}$ cells appear to be selected by high-affinity interactions in the thymus ${ }^{50,51}$; however, the mechanisms that differentiate between negative selection of $\mathrm{T}$ cells and development of regulatory $\mathrm{T}$ cells remain unclear. There is some evidence that CD28 and B71/B72 molecules may play a role in the development of regulatory $\mathrm{T}$ cells, since absence of these proteins in certain mice led to an accelerated onset of autoimmunity in the form of diabetes. ${ }^{52}$

Regulatory $\mathrm{T}$ cells, which are continuously produced by the thymus and express CD4, CD25, and glucocorticoid-induced TNF receptor (GITR), and are dependent on the X-linked forkhead/winged helix transcription factor, FOXP3, are known as naturally occurring regulatory $\mathrm{T}$ cells (Tregs). ${ }^{53}$ Our preliminary findings indicate that Tregs seem to be present in increased numbers in patients with advanced bladder cancer. In addition to Tregs, there also are IL-10 -secreting regulatory T cells, known as $\operatorname{Tr} 1$ cells, which are derived after repetitive antigenic stimulation. $\operatorname{Tr} 1$ cells also play a critical role in suppressing immune responses, and their effects seem to be inhibited by anti-IL-10 neutralizing antibody. ${ }^{54}$ Tregs and $\mathrm{Tr} 1$ cells are capable of affecting effector $\mathrm{CD} 4^{+}$and $\mathrm{CD} 8^{+} \mathrm{T}$ cells by suppressing activation and proliferation. In published preclinical studies, depletion of $\mathrm{CD} 4^{+} \mathrm{CD} 25^{+} \mathrm{T}$ cells before tumor challenge elicits effective immune responses to syngeneic tumors in otherwise nonresponding mice. ${ }^{55-59}$ In patients, increased regulatory $\mathrm{T}$ cells have been found in melanoma, lymphomas, and in gastric, lung, breast, pancreatic, and ovarian cancer. ${ }^{60-66}$ Recently, it was found that IL-2 ${ }^{67}$ and strong TCR signals ${ }^{68}$ release effector T cells from Treg-mediated suppression. Furthermore, the presence of a TLR9 ligand, known as $\mathrm{CpG}$, in a suppression assay containing APCs resulted in reduced suppression by Tregs. These results appear to be due to TLR9-triggered production of IL-6 by the APCs, which rendered conventional effector T cells insensitive to Treg-mediated suppression. ${ }^{69}$ Another report demonstrated that ligation of TLR4 or TLR9 on DCs is required for breaking Tregmediated suppression of CD8 T cells. ${ }^{70}$ Therefore, it is possible to overcome the suppressive mechanisms of regulatory $\mathrm{T}$ cells, and these recent advances must be incorporated into future vaccine strategies in bladder cancer.

Another method of relieving the inhibitory constraints on the immune system involves a novel anti-CTLA4 antibody. Anti-CTLA4, which is aimed at overcoming the previously 
described inhibitory B7-CTLA4 signal to T cells, has shown promise for the immunologic treatment of cancer and may prove beneficial in the treatment of bladder cancer. The antibody, which is a fully human monoclonal antibody ( $\operatorname{IgG}_{1}$-kappa) generated in human $\mathrm{IgG}_{1}$ transgenic mice, has been shown to be specific for the CTLA4 antigen expressed on a subset of T cells from human and nonhuman primates. Anti-CTLA4 is thought to act by interfering with the interaction between CTLA4 and B7 molecules on DCs or professional APCs, with subsequent blockade of the inhibitory modulation of $\mathrm{T}$ cell activation promoted by the CTLA4-B7 interaction.

In the case of neoplastic disease, transient or abrupt disengagement of an ongoing, therapeutically relevant T-cell response in the face of progressive tumor growth may shift the balance from induction of tumor immunity to one that favors tumor escape. Therefore, in this setting, CTLA4 blockade may actually prove beneficial for sustaining the biological activity of in vivo-primed T cells. The administration of anti-CTLA4 monoclonal antibody as monotherapy in preclinical models has demonstrated anti-tumor activity in tumor-bearing hosts, inducing tumor rejection and long-lasting immunity to rechallenge..$^{71-73} \mathrm{In}$ combination with appropriate vaccines, anti-CTLA4 therapy has also been shown to be highly effective against poorly immunogenic tumors. ${ }^{74,75}$ Collectively, preclinical findings have provided the scientific rationale and framework to initiate clinical testing of antiCTLA4 monoclonal antibody- based immunotherapy for patients with advanced cancer. Initial studies of patients with melanoma or ovarian cancer were recently completed. In three patients with metastatic melanoma, histopathologic assessment of biopsy samples of lesions revealed extensive tumor cell death accompanied by leukocytic infiltration; in two patients with metastatic ovarian carcinoma, reduced or stable expression of CA125, a biochemical serum marker of disease progression, was observed. ${ }^{76,77}$ Toxic effects associated with the anti-CTLA4 antibody seem to be mostly immune-based and involved skin (eg, rash) and gastrointestinal events (eg, diarrhea, colitis, and perforation).

We recently proposed two clinical trials with the anti-CTLA4 antibody, Ipilimumab, for patients with bladder cancer. The first is a presurgical trial aimed at defining immunologic changes within the tumor microenvironment after treatment. The second trial is aimed at determining the efficacy of therapy by treating patients who are not eligible for surgery. Both trials will investigate immunologic responses, such as $\mathrm{CD} 4^{+}, \mathrm{CD} 8^{+}$, and regulatory $\mathrm{T}-$ cell responses, generated systemically and within tumor tissues. These immunologic studies will be crucial because available biomarkers to indicate efficacy or predict toxicity of antiCTLA4 therapy are currently lacking.

\section{Conclusion}

As is true for other types of tumors, intense interest has focused on the development of targeted and immunologic approaches to the treatment of bladder cancer. Immunotherapy for bladder cancer is still in its infancy, although intravesical BCG immunotherapy already has been established in the setting of superficial bladder cancer. Novel immune-based therapies aimed at treating more advanced disease are clearly warranted. In-depth studies of tumorinfiltrating lymphocytes and their target antigens will provide important information related to immunologic mechanisms in the biology of bladder cancer. Translational studies that 
address the challenges of immune-based therapies in combination with each other, such as anti-CTLA4 antibody plus a particular vaccine, or the combination of immunotherapy with established therapies, such as chemotherapy and radiation therapy, will be necessary to further our understanding of how to combine various therapies so as to maximize the clinical benefit. It also will be necessary to elucidate the roles of the other B7 and CD28 family members in bladder cancer patients so that these pathways can serve as potential immunotherapeutic targets. Table 1 highlights some of the common immunotherapy strategies currently being explored in clinical cancer trials. Of utmost importance is that carefully designed studies integrating both rational basic science and stringent clinical protocols in human patients be conducted to further explore effective immunotherapy programs for bladder cancer.

\section{Acknowledgments}

Supported in part by the UTMDACC Bladder Cancer SPORE Career Development Award 5P50 CA091846 04 (PPCDP4), Physician Scientist Program Award and Institutional Research Grant (P. Sharma).

\section{References}

1. Coley WB. The treatment of malignant tumors by repeated inoculations of erysipelas. With a report of ten original cases. Am J Med Sci. 1893; 105:487-511.

2. Old LJ. Effect of Bacillus Calmette-Guerin (B.C.G) infection on transplanted tumours in the mouse. Nature. 1959; 184:291-292. [PubMed: 14428599]

3. Janeway CA, Medzhitov R. Innate immune recognition. Annu Rev Immunol. 2002; 20:197-216. [PubMed: 11861602]

4. Hemmi H, Takeuchi O, Kawai T, et al. A toll-like receptor recognizes bacterial DNA. Nature. 2000; 408:740-745. [PubMed: 11130078]

5. Brightbill HD, Libraty DH, Krutzik SR, et al. Host defense mechanisms triggered by microbial lipoproteins through toll-like receptors. Science. 1999; 285:732-736. [PubMed: 10426995]

6. Tsuji S, Matsumoto M, Takeuchi O, et al. Maturation of human dendritic cells by cell wall skeleton of Mycobacterium bovis bacillus Calmette-Guerin: Involvement of toll-like receptors. Infect Immun. 2000; 68:6883-6890. [PubMed: 11083809]

7. de Boer EC, Somogyi L, de Ruiter GJ, et al. Role of interleukin-8 in onset of the immune response in intravesical BCG therapy for superficial bladder cancer. Urol Res. 1997; 25:31-34. [PubMed: 9079743]

8. Thalmann GN, Sermier A, Rentsch C, et al. Urinary interleukin-8 and 18 predict the response of superficial bladder cancer to intravesical therapy with bacillus Calmette-Guerin. J Urol. 2000; 164:2129-2133. [PubMed: 11061941]

9. Jackson AM, Alexandroff AB, Kelly RW, et al. Changes in urinary cytokines and soluble intercellular adhesion molecule-1 (ICAM-1) in bladder cancer patients after bacillus CalmetteGuerin (BCG) immunotherapy. Clin Exp Immunol. 1995; 99:369-375. [PubMed: 7882559]

10. Prescott S, James K, Hargreave TB, et al. Radio-immunoassay detection of interferon-gamma in urine after intravesical Evans BCG therapy. J Urol. 1990; 144:1248-1251. [PubMed: 2122008]

11. Haaff EO, Catalona WJ, Ratliff TL. Detection of interleukin 2 in the urine of patients with superficial bladder tumors after treatment with intravesical BCG. J Urol. 1986; 136:970-974. [PubMed: 3489840]

12. De Boer EC, De Jong WH, Steerenberg PA, et al. Induction of urinary interleukin-1 (IL-1), IL-2, IL-6, and tumour necrosis factor during intravesical immunotherapy with bacillus Calmette-Guerin in superficial bladder cancer. Cancer Immunol Immunother. 1992; 34:306-312. [PubMed: 1540977] 
13. Bohle A, Gerdes J, Ulmer AJ, et al. Effects of local bacillus Calmette-Guerin therapy in patients with bladder carcinoma on immunocompetent cells of the bladder wall. J Urol. 1990; 144:53-58. [PubMed: 2359181]

14. de Boer EC, de Jong WH, van der Meijden AP, et al. Leukocytes in the urine after intravesical BCG treatment for superficial bladder cancer. A flow cytofluorometric analysis. Urol Res. 1991; 19:45-50. [PubMed: 2028562]

15. Sharma P, Jungbluth A, Gnjatic S, et al. $\mathrm{CD}^{+}$tumor-infiltrating lymphocytes as a statistically significant marker of disease recurrence and survival in transitional cell carcinoma patients. Proc Natl Acad Sci USA. (in press).

16. Zhang L, Conejo-Garcia JR, Katsaros D, et al. Intratumoral T cells, recurrence, and survival in epithelial ovarian cancer. N Engl J Med. 2003; 348:203-213. [PubMed: 12529460]

17. Schumacher K, Haensch W, Roefzaad C, et al. Prognostic significance of activated CD8(+) T cell infiltrations within esophageal carcinomas. Cancer Res. 2001; 61:3932-3936. [PubMed: 11358808]

18. Naito Y, Saito K, Shiiba K, et al. $\mathrm{CD}^{+} \mathrm{T}$ cells infiltrated within cancer cell nests as a prognostic factor in human colorectal cancer. Cancer Res. 1998; 58:3491-3494. [PubMed: 9721846]

19. Huntington ND, Tarlinton DM. CD45: Direct and indirect government of immune regulation. Immunol Lett. 2004; 94:167-174. [PubMed: 15275963]

20. Palacios EH, Weiss A. Function of the Src-family kinases, Lck and Fyn, in T cell development and activation. Oncogene. 2004; 23:7990-8000. [PubMed: 15489916]

21. Tomiyama H, Takata H, Matsuda T, et al. Phenotypic classification of human $\mathrm{CD}^{+}$Tcells reflecting their function: Inverse correlation between correlation between quantitative expression of CD27 and cytotoxic effector function. Eur J Immunol. 2004; 34:999-1010. [PubMed: 15048710]

22. Korman AJ, Peggs KS, Allison JP. Checkpoint blockade in cancer immunotherapy. Adv Immunol. 2006; 90:293-335.

23. Walunas TL, Lenschow DJ, Bakker CY, et al. CTLA-4 can function as a negative regulator of T cell activation. Immunity. 1994; 1:405-413. [PubMed: 7882171]

24. Krummel MF, Allison JP. CD28 and CTLA-4 have opposing effects on the response of T cells to stimulation. J Exp Med. 1995; 182:459-465. [PubMed: 7543139]

25. Chambers CA, Sullivan TJ, Allison JP. Lymphoproliferation in CTLA-4-deficient mice is mediated by costimulation-dependent activation of CD4 ${ }^{+}$T cells. Immunity. 1997; 7:885-895. [PubMed: 9430233]

26. Tivol EA, Borriello F, Schweitzer AN, et al. Loss of CTLA-4 leads to massive lymphoproliferation and fatal multiorgan tissue destruction, revealing a critical negative regulatory role of CTLA-4. Immunity. 1995; 3:541-547. [PubMed: 7584144]

27. Waterhouse P, Penninger JM, Timms E, et al. Lymphoproliferative disorders with early lethality in mice deficient in CTLA-4. Science. 1995; 270:985-988. [PubMed: 7481803]

28. Davis SJ, Ikemizu S, Evans EJ, et al. The nature of molecular recognition by T cells. Nat Immunol. 2003; 4:217-224. [PubMed: 12605231]

29. Chambers C, Kuhns M, Egen J, et al. CTLA-4 mediated inhibition in regulation of T cell responses: Mechanisms and manipulation in tumor immunotherapy. Annu Rev Immunol. 2001; 19:565-594. [PubMed: 11244047]

30. van der Bruggen P, Traversari C, Chomez P, et al. A gene encoding an antigen recognized by cytolytic T lymphocytes on a human melanoma. Science. 1991; 254:1643-1647. [PubMed: 1840703]

31. Boel P, Wildmann C, Sensi ML, et al. BAGE: A new gene encoding an antigen recognized on human melanomas by cytolytic T lymphocytes. Immunity. 1995; 2:167-175. [PubMed: 7895173]

32. Van den Eynde B, Peeters O, De Backer O, et al. A new family of genes coding for an antigen recognized by autologous cytolytic T lymphocytes on a human melanoma. J Exp Med. 1995; 182:689-698. [PubMed: 7544395]

33. Sahin U, Tureci O, Schmitt H, et al. Human neoplasms elicit multiple specific immune responses in the autologous host. Proc Natl Acad Sci U S A. 1995; 92:11810-11813. [PubMed: 8524854] 
34. Chen TY, Scanlan MJ, Sahin U, et al. A testicular antigen aberrantly expressed in human cancers detected by autologous antibody screening. Proc Natl Acad Sci U S A. 1997; 94:1914-1918. [PubMed: 9050879]

35. Scanlan MJ, Simpson AJ, Old LJ. The cancer/testis genes: Review, standardization, and commentary. Cancer Immun. 2004; 4:1. [PubMed: 14738373]

36. Stockert E, Jager E, Chen YT, et al. A survey of the humoral immune response of cancer patients to a panel of human tumor antigens. J Exp Med. 1998; 87:1349-1354.

37. Jager E, Nagata Y, Gnjatic S, et al. Monitoring CD8 T cell responses to NY-ESO-1: Correlation of humoral and cellular immune responses. Proc Natl Acad Sci U S A. 2000; 97:4760-4765. [PubMed: 10781081]

38. Valmori D, Dutoit V, Lienard D, et al. Naturally occurring human lymphocyte antigen-A2 restricted $\mathrm{CD}^{+} \mathrm{T}$ cell response to the cancer testis antigen NY-ESO-1 in melanoma patients. Cancer Res. 2000; 60:4499-4506. [PubMed: 10969798]

39. Yamaguchi H, Tanaka F, Ohta M, et al. Identification of HLA-A24-restricted CTL epitope from cancer-testis antigen, NY-ESO-1, and induction of a specific antitumor immune response. Clin Cancer Res. 2004; 10:890-896. [PubMed: 14871964]

40. Zarour HM, Storkus WJ, Brusic V, et al. NY-ESO-1 encodes DRB1*0401-restricted epitopes recognized by melanoma-reactive $\mathrm{CD}^{+}{ }^{+} \mathrm{T}$ cells. Cancer Res. 2000; 60:4946-4952. [PubMed: 10987311]

41. Jager E, Jager D, Karbach J, et al. Identification of NY-ESO-1 epitopes presented by human histocompatibility antigen (HLA)-DRB4*0101-0103 and recognized by CD4(+) T lymphocytes of patients with NY-ESO-1-expressing melanoma. J Exp Med. 2000; 191:625-630. [PubMed: 10684854]

42. Chen YT, Boyer AD, Viars CS, et al. Genomic cloning and localization of CTAG, a gene encoding an autoimmunogenic cancer-testis antigen NY-ESO-1, to human chromosome Xq28. Cytogenet Cell Genet. 1997; 79:237-240. [PubMed: 9605863]

43. Lethe B, Lucas S, Michaux L, et al. LAGE-1, a new gene with tumor specificity. Int J Cancer. 1998; 76:903-908. [PubMed: 9626360]

44. Sharma P, Gnjatic S, Jungbluth AA, et al. Frequency of NY-ESO-1 and LAGE-1 expression in bladder cancer and evidence of a new NY-ESO-1 T cell epitope in a patient with bladder cancer. Cancer Immun. 2003; 3:19. [PubMed: 14680360]

45. Sharma P, Shen Y, Wen S, et al. Cancer testis antigens: Expression and correlation with survival in human urothelial carcinoma. Clin Cancer Res. 2006; 12:5442-5447. [PubMed: 17000678]

46. Condon C, Watkins SC, Celluzzi CM, et al. DNA-based immunization by in vivo transfection of dendritic cells. Nat Med. 1996; 2:1122-1128. [PubMed: 8837611]

47. Doe B, Selby M, Barnett S, et al. Induction of cytotoxic T lymphocytes by intramuscular immunization with plamid DNA is facilitated by bone marrow-derived cells. Proc Natl Acad Sci U S A. 1996; 93:8578-8583. [PubMed: 8710913]

48. Nishiyama T, Tachibana M, Horiguchi Y, et al. Immunotherapy of bladder cancer using autologous dendritic cells pulsed with human lymphocyte antigen-A24-specific MAGE-3 peptide. Clin Cancer Res. 2001; 7:23-31. [PubMed: 11205913]

49. Marchand M, Punt CJ, Aamdal S, et al. Immunisation of metastatic cancer patients with MAGE-3 protein combined with adjuvant SBAS-2: A clinical report. Eur J Cancer. 2003; 39:70-77. [PubMed: 12504661]

50. Caton AJ, Cozzo C, Larkin J, et al. CD4 ${ }^{+} \mathrm{CD} 25^{+}$regulatory T cell selection. Ann NY Acad Sci. 2004; 1029:101-114. [PubMed: 15681750]

51. Jordan MS, Boesteanu A, Reed AJ, et al. Thymic selection of CD4 ${ }^{+} \mathrm{CD} 25^{+}$regulatory $\mathrm{T}$ cells induced by an agonist self-peptide. Nat Immunol. 2001; 2:301-306. [PubMed: 11276200]

52. Salomon B, Lenschow DJ, Rhee L, et al. B7/CD28 costimulation is essential for the homeostasis of the $\mathrm{CD} 4{ }^{+} \mathrm{CD} 25^{+}$immunoregulatory $\mathrm{T}$ cells that control autoimmune diabetes. Immunity. 2000; 12:431-440. [PubMed: 10795741]

53. Sakaguchi S. Regulatory T cells: Mediating compromises between host and parasite. Nat Immunol. 2003; 4:10-11. [PubMed: 12496970] 
54. Roncarolo MG, Bacchetta R, Bordignon C, et al. Type I T regulatory cells. Immunol Rev. 2001; 182:68-79. [PubMed: 11722624]

55. Shimizu J, Yamazaki S, Sakaguchi S. Introduction of tumor immunity by removing $\mathrm{CD} 25^{+} \mathrm{CD} 4^{+} \mathrm{T}$ cells: A common basis between tumor immunity and autoimmunity. J Immunol. 1999; 163:52115218. [PubMed: 10553041]

56. Onizuka S, Tawara I, Shimizu J, et al. Tumor rejection by in vivo administration of anti-CD25 (interleukin-2 receptor alpha) monoclonal antibody. Cancer Res. 1999; 59:3128-3133. [PubMed: 10397255]

57. Sutmuller RP, van Duivenvoorde LM, van Elsas A, et al. Synergism of cytotoxic T lymphocyte responses. J Exp Med. 2001; 194:823-832. [PubMed: 11560997]

58. Golgher D, Jones E, Powrie F, et al. Depletion of $\mathrm{CD} 25^{+}$regulatory cells uncovers immune responses to shared murine tumor rejection antigens. Eur J Immunol. 2002; 32:3267-3275. [PubMed: 12555672]

59. Gray CP, Arosio P, Hersey P. Association of increase levels of heavy-chain ferritin with increased $\mathrm{CD}^{+}{ }^{+} \mathrm{CD} 25^{+}$regulatory $\mathrm{T}$ cell levels in patients with melanoma. Clin Cancer Res. 2003; 9:25512559. [PubMed: 12855630]

60. Marshall NA, Christie LE, Munro LR, et al. Immunosuppressive regulatory T cells are abundant in the reactive lymphocytes of Hodgkin lymphoma. Blood. 2004; 103:1755-1762. [PubMed: 14604957]

61. Woo, Ey, Chu, CS., Goletz, TJ., et al. Regulatory CD4(+)CD25(+) T cells in tumors from patients with early-stage non-small cell lung cancer and late-stage ovarian cancer. Cancer Res. 2001; 611:4766-4772.

62. Woo EY, Yeh H, Chu CS, et al. Cutting edge: Regulatory T cells from lung cancer patients directly inhibit autologous T cell proliferation. J Immunol. 2002; 168:4272-4276. [PubMed: 11970966]

63. Ichihara F, Kono K, Takahashi A, et al. Increased populations of regulatory $\mathrm{T}$ cells in peripheral blood and tumor-infiltrating lymphocytes in patients with gastric and esophageal cancers. Clin Cancer Res. 2003; 9:4404-4408. [PubMed: 14555512]

64. Sasada T, Kimura M, Yoshida Y, et al. $\mathrm{CD} 4^{+} \mathrm{CD} 25^{+}$regulatory T cells in patients with gastrointestinal malignancies: Possible involvement of regulatory $\mathrm{T}$ cells in disease progression. Cancer. 2003; 98:1089-1099. [PubMed: 12942579]

65. Wolf AM, Wolf D, Steurer M, et al. Increase of regulatory T cells in the peripheral blood of cancer patients. Clin Cancer Res. 2003; 9:606-612. [PubMed: 12576425]

66. Liyanage UK, Moore TT, Joo HG, et al. Prevalence of regulatory T cells is increased in peripheral blood and tumor microenvironment of patients with pancreas or breast adenocarcinoma. $\mathrm{J}$ Immunol. 2002; 169:2756-2761. [PubMed: 12193750]

67. Thornton AM, Shevach EM. Suppressor effector function of $\mathrm{CD} 4{ }^{+} \mathrm{CD} 25^{+}$immunoregulatory T cells is antigen nonspecific. J Immunol. 2000; 164:183-190. [PubMed: 10605010]

68. Baecher-Allan C, Viglietta V, Hafler DA. Inhibition of human CD4(+)CD25(+high) regulatory T cell function. J Immunol. 2002; 169:6210-6217. [PubMed: 12444126]

69. Pasare C, Medzhitov R. Toll pathway-dependent blockade of CD4 ${ }^{+} \mathrm{CD} 25^{+} \mathrm{T}$ cell-mediated suppression by dendritic cells. Science. 2003; 299:1033-1036. [PubMed: 12532024]

70. Yang Y, Huang CT, Huang X, et al. Persistent Toll-like receptor signals are required for reversal of regulatory T cell-mediated CD8 tolerance. Nat Immunol. 2004; 5:508-515. [PubMed: 15064759]

71. Leach DR, Krummel MF, Allison JP. Enhancement of antitumor immunity by CTLA-4 blockade. Science. 1996; 271:1734-1736. [PubMed: 8596936]

72. Yang YF, Zou JP, Mu J, et al. Enhanced induction of antitumor T cell responses by cytotoxic T lymphocyte-associated molecule-4 blockade: The effect is manifested only at the restricted tumorbearing stages. Cancer Res. 1997; 57:4036-4041. [PubMed: 9307290]

73. Ryan MH, Bristol JA, McDuffie E, et al. Regression of extensive pulmonary metastases in mice by adoptive transfer of antigen-specific $\mathrm{CD} 8{ }^{+} \mathrm{CTL}$ reactive against tumor cells expressing a naturally occurring rejection epitope. J Immunol. 2001; 167:4286-4292. [PubMed: 11591751]

74. van Elsas A, Hurwitz AA, Allison JP. Combination immunotherapy of B16 melanoma using anticytotoxic T lymphocyte-associated antigen 4 (CTLA-4) and granulocyte/macrophage colonystimulating factor (GM-CSF)-producing vaccines induces rejection of subcutaneous and metastatic 
tumors accompanied by autoimmune depigmentation. J Exp Med. 1999; 190:355-366. [PubMed: 10430624]

75. van Elsas A, Sutmuller RP, Hurwitz AA, et al. Elucidating the autoimmune and antitumor effector mechanisms of a treatment based on cytotoxic T lymphocyte antigen- 4 blockade in combination with a B16 melanoma vaccine: Comparison of prophylaxis and therapy. J Exp Med. 2001; 194:481-489. [PubMed: 11514604]

76. Hodi FS, Mihm MC, Soiffer RJ, et al. Biologic activity of cytotoxic T lymphocyte-associated antigen 4 antibody blockade in previously vaccinated metastatic melanoma and ovarian carcinoma patients. Proc Natl Acad Sci U S A. 2003; 100:4712-4717. [PubMed: 12682289]

77. Phan GQ, Yang JC, Sherry RM, et al. Cancer regression and autoimmunity induced by cytotoxic T lymphocyte-associated antigen 4 blockade in patients with metastatic melanoma. Proc Natl Acad Sci U S A. 2003; 100:8372-8377. [PubMed: 12826605] 


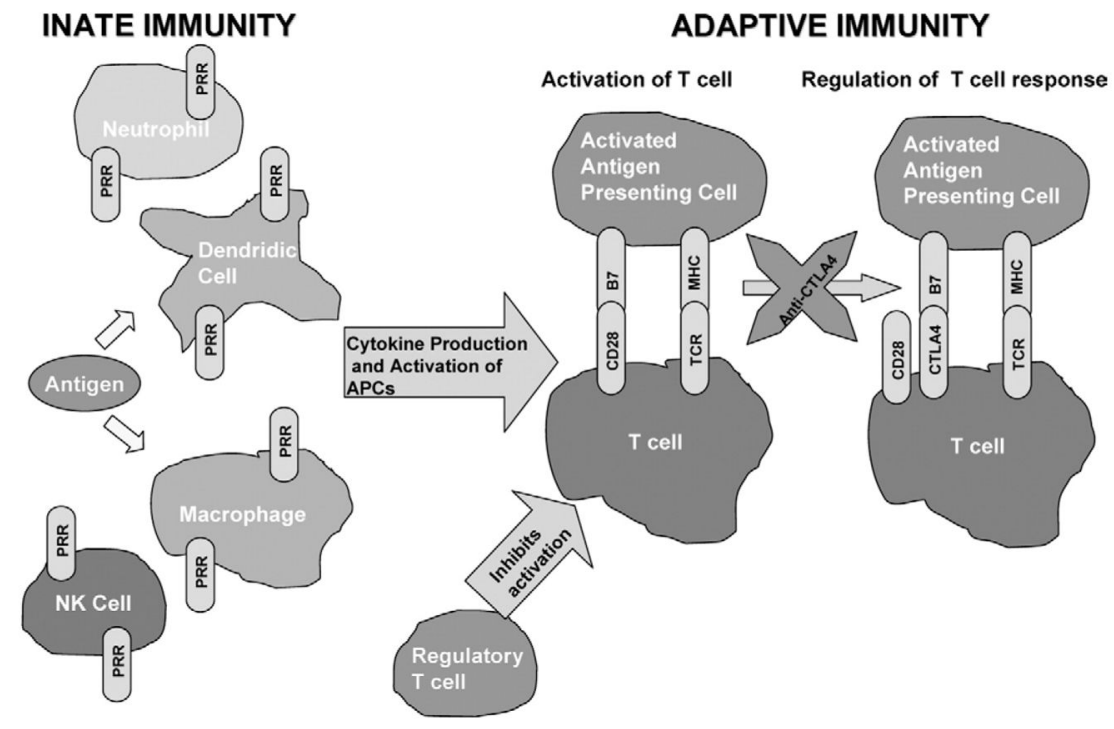

Figure 1.

Antigen is presented in the context of major histocompatibility (MHC) molecules to T-cell receptor (TCR), referred to as signal 1, and costimulatory molecules, such as CD28 and B7, provide signal 2 to allow for T-cell activation. T-cell responses are then regulated by CTLA4 interaction with B7 so as to maintain homeostasis. Regulatory $\mathrm{T}$ cells can also suppress Tcell activation. In cancer patients, it is possible to interfere with the CTLA4-B7 interactions with anti-CTLA4 antibody thereby promoting enhanced T-cell responses. 


\section{Table 1}

Areas Targeted by Immunotherapy in Current Clinical Trials

\begin{tabular}{|c|c|c|}
\hline Target Area & Study A & \\
\hline \multirow[t]{4}{*}{ Innate immune system } & \multicolumn{2}{|c|}{ Immunologic adjuvants, such as: } \\
\hline & 1 & GM-CSF \\
\hline & 2 & CpG moiety \\
\hline & 3 & $\mathrm{BCG}$ \\
\hline \multirow[t]{2}{*}{ Presentation of antigen by APCs } & $\mathbf{1}$ & DNA-encoded antigens \\
\hline & 2 & DCs matured and pulsed with antigen in vitro before administration to patients \\
\hline \multirow[t]{2}{*}{ Specific T-cell responses } & 1 & Antigens that are known to be recognized by $\mathrm{T}$ cells in vitro \\
\hline & 2 & In vitro stimulation of $\mathrm{T}$ cells before administration to patients \\
\hline \multirow[t]{2}{*}{ Nonspecific immune responses } & 1 & Intact tumor cells \\
\hline & 2 & Tumor cell lysates \\
\hline Inhibitory mechanism on $\mathrm{T}$ cells & 1 & Anti-CTLA4 antibody \\
\hline \multirow[t]{3}{*}{ Combination strategies } & 1 & Vaccine plus immunologic adjuvant \\
\hline & 2 & Intact tumor cells transfected with immunologic adjuvant \\
\hline & 3 & Anti-CTLA4 plus vaccine \\
\hline
\end{tabular}

Abbreviations: APCs, antigen-presenting cells; GM-CSF, granulocyte-macrophage colony-stimulating cells; BCG, bacillus Calmette-Guérin; DCs, dendritic cells. 